\title{
Nuclear envelope: a new frontier in plant mechanosensing?
}

\author{
Kateryna Fal $^{1} \cdot$ Atef Asnacios $^{2} \cdot$ Marie-Edith Chabouté $^{3}$ - Olivier Hamant ${ }^{1}$ (B)
}

Received: 19 April 2017 / Accepted: 28 July 2017 / Published online: 12 August 2017

(C) The Author(s) 2017. This article is an open access publication

\begin{abstract}
In animals, it is now well established that forces applied at the cell surface are propagated through the cytoskeleton to the nucleus, leading to deformations of the nuclear structure and, potentially, to modification of gene expression. Consistently, altered nuclear mechanics has been related to many genetic disorders, such as muscular dystrophy, cardiomyopathy and progeria. In plants, the integration of mechanical signals in cell and developmental biology has also made great progress. Yet, while the link between cell wall stresses and cytoskeleton is consolidated, such cortical mechanical cues have not been integrated with the nucleoskeleton. Here, we propose to take inspiration from studies on animal nuclei to identify relevant methods amenable to probing nucleus mechanics and deformation in plant cells, with a focus on microrheology. To identify potential molecular targets, we also compare the players at the nuclear envelope, namely lamina and LINC complex, in both plant and animal nuclei. Understanding how mechanical signals are transduced to the nucleus across kingdoms will likely have essential implications in development (e.g. how mechanical cues add robustness to gene expression patterns), in the nucleoskeleton-
\end{abstract}

This article is part of a Special Issue on 'IUPAB Edinburgh Congress' edited by Damien Hall.

Olivier Hamant

olivier.hamant@ens-lyon.fr

1 Laboratoire Reproduction et Développement des Plantes, Université de Lyon, ENS de Lyon, UCB Lyon 1, CNRS, INRA, 69342 Lyon, France

2 Laboratoire Matières et Systèmes Complexes, Université Paris-Diderot and CNRS, UMR 7057, Sorbonne Paris Cité, Paris, France

3 Institut de Biologie Moléculaire des Plantes, CNRS, Université de Strasbourg, 67000 Strasbourg, France cytoskeleton nexus (e.g. how stress is propagated in turgid/ walled cells), as well as in transcriptional control, chromatin biology and epigenetics.

Keywords Nuclear envelope $\cdot$ Lamina $\cdot$ LINC complex . Cytoskeleton · Chromatin - Mechanical force .

Microrheology · Plants

\section{Introduction}

Plants, like animals, respond to mechanical stimuli. This is probably most obvious when looking at a section of a tree branch: its anatomical asymmetry reveals the existence of so-called "reaction wood", the product of an active mechanical reinforcement that matches the asymmetric load caused by gravity. In recent years, plant mechanosensing research is turning more and more towards cell and molecular aspects, from cytoskeleton behaviour to the regulation of gene expression following mechanical perturbations (Braam 2005; Hamant 2013; Monshausen and Haswell 2013; Coutand et al. 2009; Geitmann 2010). Although plants exhibit specific cell features, like a stiff cell wall (in the MPa range) and high hydrostatic pressure (turgor pressure, also in the MPa range), both kingdoms display a number of comparable responses to mechanical cues.

Animal cells respond to their mechanical environment, notably through interactions with their extracellular matrix (see e.g. Vogel and Sheetz 2006, 2009; Discher et al. 2005, 2009). Plant and animal extracellular matrices are structurally and chemically very different. From the signalling point of view, the quasi absence of true integrins in plant genomes (for an exception, see Knepper et al. 2011) needs to be put in context against the high number of receptor-like kinase in plants. Several of these proteins can interact with wall components 
(e.g. the WAK receptor with the backbone of pectins; Anderson et al. 2001; Wolf et al. 2012), a bit like integrin with fibronectin, arguably. Interestingly, one such receptor-like kinase, FERONIA, contributes to mechanoperception in Arabidopsis roots (Shih et al. 2014).

At the plasma membrane, a role of tension in cell polarity has been shown in both kingdoms, notably through the inhibitory role of membrane tension on endocytosis, that can trap transporters (e.g. Heisler et al. 2010; Nakayama et al. 2012) or receptors (e.g. Pouille et al. 2009) in polar domains (for a comparative review between plants and animals, see Asnacios and Hamant 2012). Similarly, in both kingdoms, membrane tension should lead to membrane thinning, which, in turn, changes the conformation of mechanosensitive channels, leading to their opening (Haswell et al. 2011).

Inside the cell, the cortical cytoskeleton is a focus of mechanotransduction research in both plants and animals. However, one must highlight here that most animal cells exhibit an actomyosin-rich cortex, consistent with their contractility, whereas plant cells have a microtubule-rich cortex: cortical microtubules (CMTs) guide the cellulose synthase complex at the plasma membrane, thus channelling the production of cellulose microfibrils in the wall (Green 1962; Paredez et al. 2006). Both actomyosin and microtubules respond to mechanical cues. In animal cells for instance, myosin is preferentially recruited on tensed membrane, providing a positive feedback loop for cell contraction, amenable to generating tissue folding (Lecuit and Lenne 2007; Sherrard et al. 2010). In plants, cortical microtubules are oriented in the direction of maximal tension, thereby controlling the deposition of stiff cellulose microfibrils, through CMT-cellulose synthase complex guidance, in the wall (Green and King 1966; Williamson 1990; Hejnowicz et al. 2000). Interestingly, this mechanical feedback has also been proposed to enhance tissue folding in plant tissues, through the local channelling of growth direction (Hamant et al. 2008; Uyttewaal et al. 2012).

Mechanical stimuli at the extracellular matrix, membrane and cytoskeleton may be transmitted to the cell nucleus, notably because the nuclear envelope is physically interacting with the cytoskeleton (Ingber 2003; Wang et al. 2009; Dahl et al. 2010; Fedorchak et al. 2014). Yet, despite the established impact of mechanical forces on gene expression in all kingdoms, the nexus between mechanical stress and nucleus remains largely unexplored in plants. Nonetheless, some recent results may point in that direction, albeit quite indirectly. The chromatin modifying enzyme SDG8 is required for the control of gene expression in response to touch (Cazzonelli et al. 2014). More recently, in a screen for touch-insensitive mutants, the transcriptional regulator VIP3, a member of the Pafl complex, was identified (Jensen et al. 2017), suggesting that nuclear factors might have a stronger role in mechanotransduction than anticipated. Here, we propose to investigate the possible contribution of the nuclear envelope in that framework. To do so, we discuss biophysical methods to probe plant nuclei and the coupling between cytoskeleton and nucleoskeleton; we also compare the putative pathways and molecular targets involved in nuclear mechanotransduction in plant and animal cells (Table 1).

\section{The molecular players of mechanotransduction at the nuclear envelope in animal cells}

The structure of the nuclear envelope is stabilised by a network of integral proteins, anchored to the inner nuclear membrane (Zwerger and Medalia 2013; Gruenbaum and Foisner 2015). Among those, numerous proteins and protein complexes ensure continuous selective transport of molecules between the cytoplasm and caryoplasm (Schirmer et al. 2003; Korfali et al. 2012). Nuclear pore complexes prevent the free diffusion of macromolecules (radius $\geq 2.5 \mathrm{~nm}$, corresponding to a protein of ca. $35-40 \mathrm{kDa}$ in mass). They are composed of multiple constituent proteins (nucleoporins or Nups), containing the phenylalanine-glycine (FG) repeats and anchored to a membrane of the nuclear envelope (Field et al. 2014; Obado et al. 2016; Mohr et al. 2009). The transport of large macromolecules through the nuclear envelope is supported by nuclear transport proteins (NTRs, importins/exportins) that bind the target cargo molecules and assist their passage through the FG repeat-rich nuclear pore complex core. One of the most notable players in the asymmetric directional transport, Ran GTPase, has its GTP-bound form in the nucleus opposing the GDP-bound one in the cytoplasm (Schmidt and Görlich 2016). Disruption of nuclear pore complexes following an oxidative stress had been shown to result in nuclear aggregation of cytosolic proteins, a phenotype associated with neurodegenerative disease (D'Angelo et al. 2009). Although nuclear pore complexes may have an indirect role in shaping nuclei and mechanosensing, here, we will focus on the two main structural components of the nuclear envelope, namely the LINC complex and the lamina (Fig. 1).

The LINC complex consists of SUN (homologous to Sad1p and UNc-84) and Klarsicht/ANC-1/Syne-1 homology (KASH) proteins, which span the nuclear envelope and connect the nucleoskeleton with the cytoskeleton.

Mammalian nesprin belong to a large family of actinbinding proteins, encoded by nesprin 1 and 2 genes. Containing the c-terminal KASH domain, they are homologous to Drosophila melanogaster protein Klarsicht and are located at the outer nuclear membrane (Mosley-Bishop et al. 1999; Apel et al. 2000; Mislow et al. 2002; Zhen et al. 2002; Padmakumar et al. 2004, 2005).

Several SUN homology domain proteins have been identified in mammalian cells (Hagan and Yanagida 1995). SUN1 and SUN2 have a considerable degree of functional redundancy. They localise to the inner nuclear membrane and interact with lamins (see below) by KASH domain proteins, 


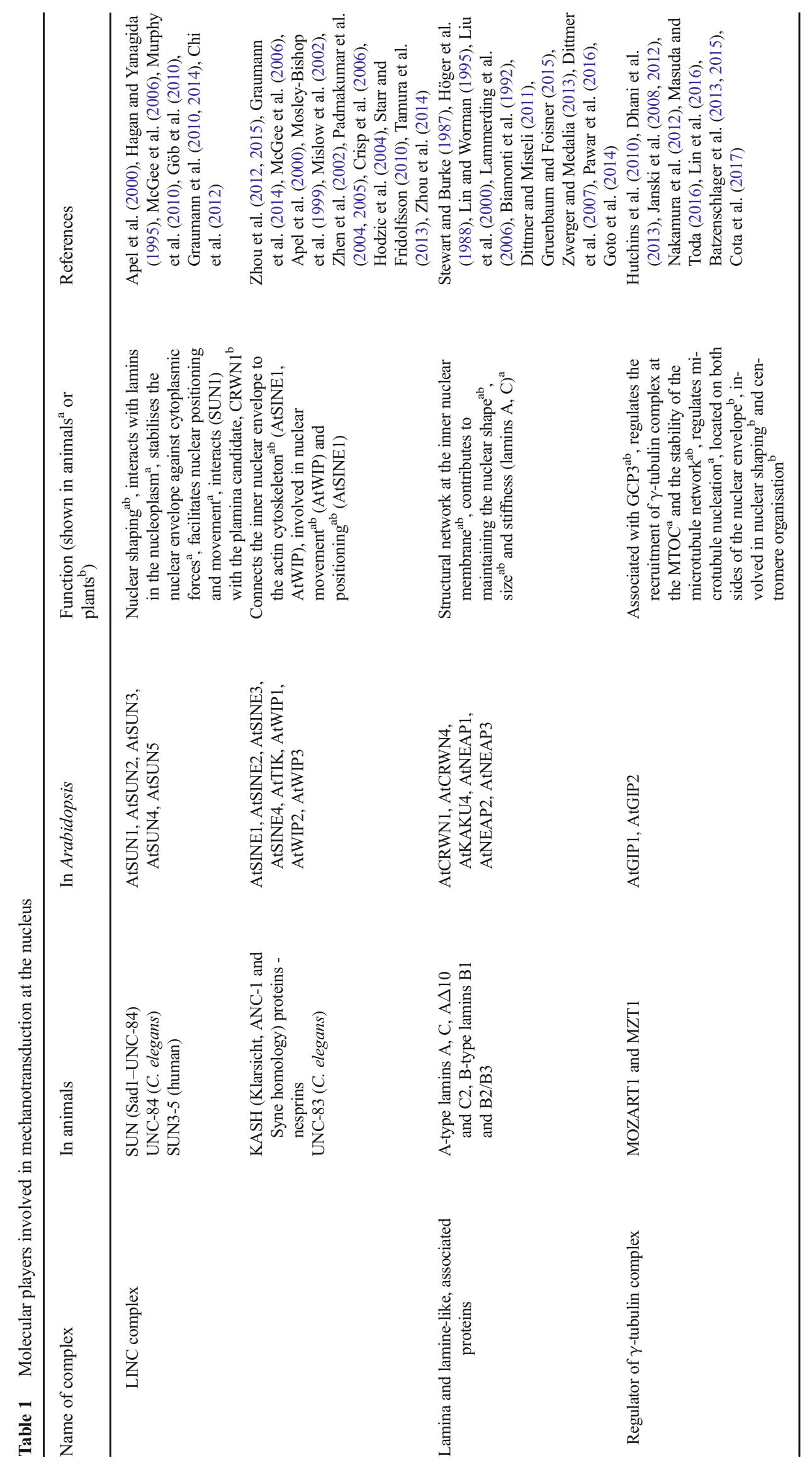




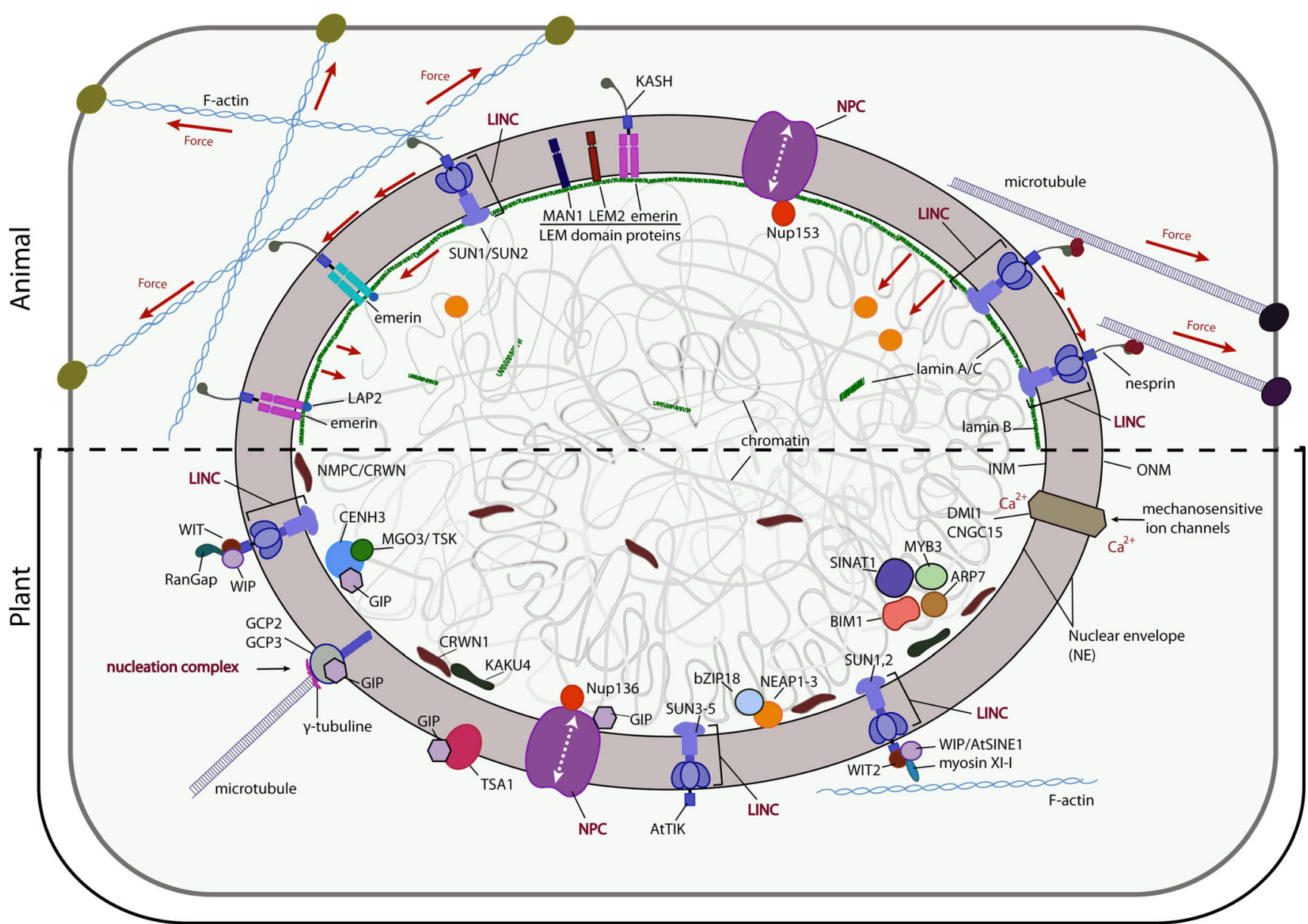

Fig. 1 Mechanosensing at the nuclear envelope in animals and candidates in plants. The upper part of the figure illustrates the elements involved in nucleus mechanosensing in animals; the lower part is dedicated to the putative components of mechanosensing at the plant nucleus. The nuclear pore complexes, anchored to nuclear envelope (NE) ensure the selective transport of molecules through the inner and outer nuclear membranes (INM and ONM, respectively). At the nuclear pore complex, nucleoporins Nup153 (animals) and Nup136 (plants) have been identified. LINC complexes are composed of KASH domain nesprins and SUN domain-containing proteins in animals. In plants, LINC complexes are represented by SUN proteins (animal homologues) and KASH proteins (e.g. WIP, WIT), with no structural homology to their functional equivalents in animals. The LINC complex couples the cytoskeleton to the nucleoskeleton. The inner nuclear membrane of animal nuclei harbors the LEM domain family proteins (LEM2, MAN1, emerin) that interact with lamins at the periphery of the nucleus. At the inner membrane of the plant nucleus, the NEAP1-3 proteins interact with bZIP18 and chromatin. The plant lamin-like nuclear matrix components (NMCPs), also called crowded nuclei (CRWN), have several interactors (KAKU4, ARP7, BIM1, MYB3 and SINAT1). Plant ion channel complex comprising DMI1-CNGC15 is localised on both sides of the nuclear envelope. GIP proteins, present on both sides of the nuclear envelope, function as a component of microtubule nucleation complexes (at the outer nuclear membrane), they are associated with the nuclear pore complex and TSA1, and colocalise with centromeres and epigenetic regulator $\mathrm{MGO} 3 / \mathrm{TSK}$ connecting the inner nuclear envelope to the actin cytoskeleton (Crisp et al. 2006; Padmakumar et al. 2004, 2005; Hodzic et al. 2004; Starr and Fridolfsson 2010). The localisation of SUN1 near nuclear pore complexes at the inner nuclear membrane may reflect a role of SUN1 for the recruitment of prelamins for nuclear lamina assembly at NPCs (Liu et al. 2007). On the contrary, SUN2 are located in NPC-free regions and the nesprin2 Giant (NUANCE) and SUN2 have been shown to colocalise with actin during the nuclear movement in polarising fibroblasts (Lombardi et al. 2011; Arsenovic et al. 2016; Khatau et al. 2012; Lüke et al. 2008; Thorpe and Lee
2017) and nesprin 3 was shown to be required for actin remodelling and cell polarisation in response to shear stress (Morgan et al. 2011). The controlled migration of nuclei in the C. elegans $\mathrm{P}$ cells (3-4 mm diameter moving over $150 \mathrm{~nm}$ between the body wall muscle and the worm's cuticle) is dependent on interactions between canonical SUN and KASH proteins, UNC-84 and UNC-83 (microtubule recruitment) or ANC-1 (actin recruitment) (Stewart-Hutchinson et al. 2008). Recently, human muscle cell precursors were shown to require nesprin 1 to sense the stiffness of the extracellular matrix, highlighting the central role of the LINC complex and force 
transmission through the nuclear membrane for the cell to respond and adapt to its mechanical environment (Schwartz et al. 2017).

The LINC complex is sensitive to low stress magnitude (Chambliss et al. 2013). In particular, low shear stresses may only activate the actin cap-based physical pathway (small subset of actin fibres connected to the nuclear envelope through the LINC complex, NUANCE and nesprin3 that form the perinuclear actin cap), while high shear stresses would engage both this LINC/actin cap-based physical pathway as well as previously established biochemical pathways, such as the integrin activation through the c-Src and phosphoinositide 3kinase cascade (Shyy and Chien 2002; Tzima et al. 2005), NADPH oxidase inactivation (Godbole et al. 2008) and prostaglandins induction through the cyclooxygenase-2 (Di Francesco et al. 2009) (also reviewed in Lu and Kassab 2011).

Inside the nucleus, the lamina is composed of helix-rich fibrillar lamin proteins that form a structural network near the inner nuclear membrane (Goldman et al. 2002; Gruenbaum and Foisner 2015; Zwerger and Medalia 2013). The lamina maintains the nuclear shape and size, and is indirectly related to the cytosolic cytoskeleton via the LINC complex (Crisp et al. 2006). Lamins assist the recruitment of the LEM (LAP2, emerin and MAN1) family to the nuclear envelope and take part in nuclear pore complex stabilisation (Gesson et al. 2016; Margalit et al. 2005; Shaklai et al. 2007; Shimi et al. 2015; Xie et al. 2016). They are also involved in chromatin organisation and gene regulation (through heterochromatin-associated proteins and because certain transcription factors can be harboured at the nuclear envelope), as well as nuclear mechanical stability (Schirmer et al. 2003; Shimi et al. 2015; Korfali et al. 2012; Gruenbaum and Foisner 2015; Xie et al. 2016; Paddy et al. 1990; Solovei et al. 2013; Margalit et al. 2005; Wilson and Foisner 2010).

In mammals, two types of lamins have been identified. Lamins A, C, A $\Delta 10$ and $\mathrm{C} 2$ belong to the A-type and are the products of the alternative splicing of a single gene, LMNA (Nakajima and Abe 1995; Peter et al. 1989, reviewed in Dittmer and Misteli 2011). They are expressed in differentiated and developmentally regulated cells (Furukawa et al. 1994; Lin and Worman 1993; Liu et al. 2000). Another group, the Btype lamins, comprises $\mathrm{B} 1$ and $\mathrm{B} 2 / \mathrm{B} 3$ proteins, are encoded by two independent genes (LMNB1 and $L M N B 2$ ) and are constitutively expressed in all cell types (Peter et al. 1989; Stewart and Burke 1987; Höger et al. 1988; Lin and Worman 1995; Liu et al. 2000; Biamonti et al. 1992, reviewed in Dittmer and Misteli 2011). In murine dermal fibroblasts, lamin A/C is localised throughout the nucleus, associates with the chromatin-binding protein lamina-associated polypeptide (LAP) $2 \alpha$ and interacts with euchromatin (Gesson et al. 2016). In contrast, lamin B1 has been mainly detected at the nuclear periphery and was only found to be associated with heterochromatin. In LAP $2 \alpha$-deficient cells, loss of lamin $\mathrm{A} / \mathrm{C}$ at heterochromatic regions is correlated with increased gene expression, suggesting a role of lamins $\mathrm{A} / \mathrm{C}$ in euchromatin regulation (Gesson et al. 2016; Shaklai et al. 2007).

The amount of lamin A positively correlates with nuclear and tissue stiffness, and deficiency in lamins $\mathrm{A} / \mathrm{C}$ has been associated with distorted and fragile nuclei (Liu et al. 2000; Vigouroux et al. 2001; Swift et al. 2013); therefore, it has been suggested that lamins $\mathrm{A} / \mathrm{C}$ play a role in the nucleus response to mechanical strain. The depletion of lamins $\mathrm{A} / \mathrm{C}$ results in significant decrease of nuclear stiffness, highlighting their primary role in nuclear structure, while also indicating a contribution of other nuclear components to the remaining stiffness (Dahl et al. 2005; Pajerowski et al. 2007; Lammerding et al. 2006). The loss of LINC complex or the actin bundles does not rescue nuclear lamina defects; however, it leads to a decrease of size and quantity of chromatin hernias (i.e. chromatin exiting the nucleus upon nuclear envelope rupture) (Hatch and Hetzer 2016). In contrast, the nucleus rupture in cells treated with actin-depolymerising drugs could be rescued by mechanically constraining the nucleus (Hatch and Hetzer 2016). Although this is debated, the rupture of nuclear envelope with defects in lamina organisation could be caused by an increase in intranuclear pressure from actin-based nucleus confinement (Furusawa et al. 2015; Schreiner et al. 2015; Hatch and Hetzer 2016). Interestingly, recent experiments demonstrated that the nucleus exhibits two deformation regimes in response to mechanical strain. The main component that contributes to maintenance of nuclear shape at small deformations was identified to be the chromatin itself, while lamins $\mathrm{A} / \mathrm{C}$ play a role in the stiffening of nuclei when subjected to larger deformations (Stephens et al. 2017).

\section{Microrheometry to analyse nucleus mechanics and the coupling between cytoskeleton and nucleoskeleton}

Beyond the identification of the molecular players at the nuclear envelope, their formal integration with mechanical cues has been possible thanks to the development of micromechanical methods and techniques. As shown above, a key landmark in this endeavour was the identification of a central role of the LINC complex in mechanotransduction from cell surface to chromatin (Dahl and Kalinowski 2011). Before investigating this question in plant nuclei, we review here some of the methods that have been used to analyse the nuclear mechanics of animal cells, focusing on the most direct method, micrometry (Box 1, Fig. 2). 


\section{Box 1. Rheometry}

Rheometry, from the Greek word "rheos" (flow), is the discipline dedicated to the quantitative characterisation of the rheological properties of materials, i.e. the way they deform and flow when submitted to external forces. Rheometry techniques can essentially be divided into two classes: active and passive rheometry. In active rheometry, one applies a stress (force per unit area, dimension of a pressure), either constant (static) or variable (dynamic rheometry), and measures the induced sample strain (dimensionless deformation, i.e. as a percentage of the initial sample size). Basically, the relationship between stress and strain defines the mechanical behaviour of the sample, which is quantified by a modulus (elastic and/or viscous, with dimension of a pressure). Most studies on nuclear mechanics were carried out with active microrheometry techniques. In passive microrheometry, the spontaneous movement of nanoparticles inside the cytoplasm and/or the nucleus (either injected synthetic ones or components of the nuclear material) is tracked and viscoelastic moduli are calculated from the mean square displacement (MSD, a measure of the mean distance travelled by a particle after a given time).

Among micromechanical techniques, micropipette aspiration is probably the one that was used most often for nuclear mechanics characterisation. Rheometric measurements with micropipettes were first done on single cells (Hochmuth 2000), but were rapidly extended to isolated nuclei since micropipettes constitute an "all-in-one" rheometer and micromanipulation tool (Guilak et al. 2000): by applying a pressure drop on a micrometric pipette, one can easily aspirate a single nucleus and monitor its elongation in the glass tube (e.g. with fluorescence microscopy) and observe the relevant to concomitant deformation of a given element of the nucleoskeleton. In particular, micropipette aspiration was successfully used to define the role of lamins in nuclear mechanics (Dahl et al. 2004, 2005), and their implication in differentiation (Pajerowski et al. 2007; Shin et al. 2013), their adaptation to the rigidity of the extracellular matrix and tissues (Swift et al. 2013; Buxboim et al. 2014), as well as their involvement in major diseases (e.g. Dahl et al. 2006).

Beyond the focus on lamins from the mechanics of isolated nuclei, micropipettes were also used to deform nuclei inside living cells, in order to determine the proteins involved in the mechanical coupling between the cytoskeleton and the nucleoskeleton. For instance, nuclei lacking emerin (linker protein from the inner nuclear membrane) were shown to display altered elasticity (Rowat et al. 2006). More recently, the ability of nuclei to recover from micropipette-imposed deformations was shown to depend on intermediate filaments, SUN proteins and lamins, but neither on microtubules nor actin filaments (Neelam et al. 2015).

In parallel to micropipette measurements, different cantilever-based techniques were used to compress (global scale deformation: parallel microplates, compressive cell device) or to indent (local deformation: atomic force microscope) cells or isolated nuclei (Bao and Suresh 2003; Thoumine et al. 1999; Broers et al. 2004; Schäpe et al. 2009). In these techniques, the cantilever (basically a spring of calibrated stiffness) is deflected to apply a well-defined stress on the sample, and the strain is determined through image analysis, from cantilever deflection or/and displacement, depending on the particular technique and protocol. Parallel microplates measurements were among the first to show mechanical continuity between cytoskeleton and nucleoskeleton, and to quantitatively compare their elastic moduli, the nucleus being about ten times stiffer than the cytosol (Thoumine et al. 1999; Caille et al. 2002). As mentioned above, the observation that cells lacking lamin A exhibit lowered stiffness and bursting force than wild-type counterparts was notably shown using compressive cell device measurements on mouse embryonic fibroblasts, indicating that the nucleus contributes to the overall cell resistance to deformation, in line with clinical phenotypes observed in muscles dystrophies due to mutation in the lamin $\mathrm{A} / \mathrm{C}$ gene (laminopathies) (Broers et al. 2004).

When used to measure the local rheological properties of isolated nuclei, atomic force microscopy led to results comparable to those retrieved from global probing with micropipettes, with a prominent role of lamins in stiffening the nuclear envelope and nucleus (Dahl et al. 2005; Schäpe et al. 2009). Interestingly, by probing nuclei from Drosophila embryos, it was shown that the inner nuclear membrane protein Kuk stiffens the nuclear envelope and controls its shape through coupling to polymerising microtubule bundles (Hampoelz et al. 2011). Beyond these atomic force microscopy measurements on isolated nuclei, a custom-made sharp-needle atomic force microscopy probe has been recently introduced to measure nucleus modulus in situ, by penetrating the cell and nuclear membranes with minimal injury. The authors showed that cell-embedded nuclei are stiffer than isolated ones, probably due to strain stiffening, i.e. tension transferred to the nucleus from the cytoskeleton (Liu et al. 2014).

Among local rheometric measurements, magnetic twisting cytometry is certainly one of the most popular in the field of cell rheology (Fabry et al. 2001). A ferromagnetic bead bound to cell-surface integrins is twisted thanks to a rotating magnetic field, leading to bead displacement and cyclic deformation of the cell cytoskeleton, which is anchored to surface adhesion complexes. However, in the context of nuclear mechanics and mechanosensing, magnetic twisting cytometry was mainly used as a means to test the hypothesis of a directed force transmission from cell-surface receptors to the nucleus through the tensed cytoskeletal polymer network. Indeed, while applying small cyclic bead displacements at the cell surface (in the range of $\sim 0.4 \mu \mathrm{m}$ ), stress was found to propagate inside the nucleus, the nucleoli being deformed upon external mechanical stimulation (Maniotis et al. 1997; Hu 


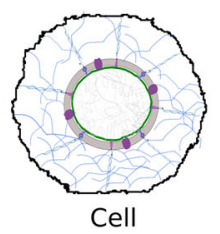

Cell

a

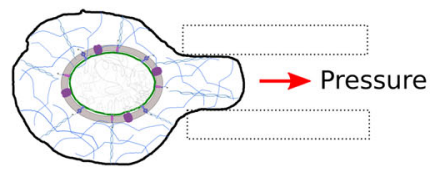

b
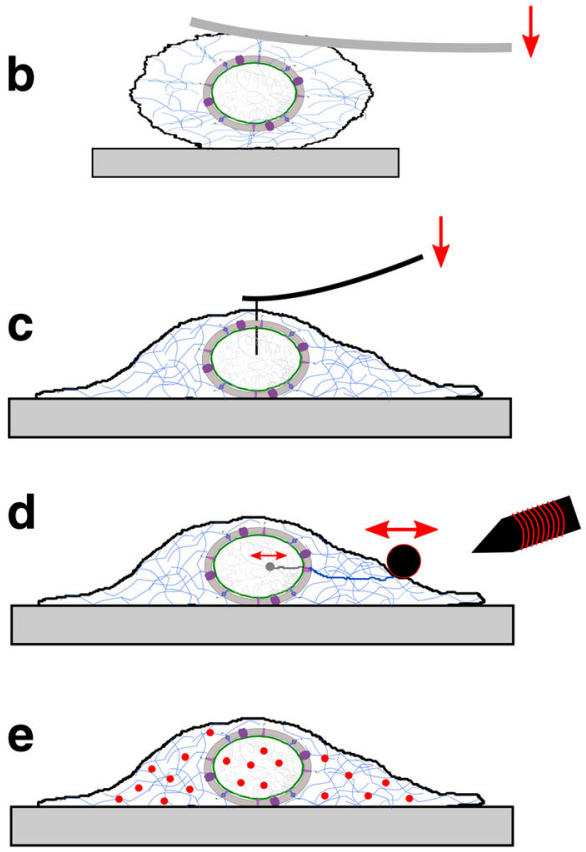

Fig. 2 Mechanical measurements on whole cells (left) and on isolated nuclei (right). a Cell/nucleus deformed by micropipette aspiration. b, c Techniques based on cantilever (spring of calibrated stiffness) deflection. b Compression between microplates, global deformation. Micropipettes and parallel microplates allow direct comparison between cell and nucleus mechanics. $\mathbf{c}$ Local probing of the nucleus. Left: in situ characterisation of the nucleus mechanical properties using a custom-made sharp atomic force microscope tip to penetrate cell and nucleus membranes. Right: regular AFM tip used to probe the nucleus surface. d Magnetic bead-

et al. 2005). Protein complexes from the Cajal body could also undergo cyclic stretch until complete dissociation (Poh et al. 2012).

A slightly different version of magnetic bead-based microrheometers, called magnetic tweezers, uses controlled electric currents to create variable magnetic field gradients to pull on magnetic beads bound to the cell surface (Bausch et al. 1998). Combining magnetic tweezers with cell culture on stretchable membranes, mouse embryonic fibroblasts lacking lamin A were shown to have softer nuclei, as well as overall decreased cell stiffness (Lammerding et al. 2004), in line with the results observed with compression experiments (Broers et al. 2004), underlining, once again, the nuclear contribution to whole-cell mechanics and its possible role in muscular based microrheometry. Left: a twisting magnetic field applies oscillations on a bead bound to the cell surface and oscillations are transmitted to nuclear components through the cytoskeleton, the LINC complex and the lamina. Right: successive current pulses lead to repeated magnetic traction forces applied on a bead bound to the nucleus surface, causing nucleus stiffening (mechanosensing). e Passive microrheology based on nano-particle tracking. Comparison between particle movements in the cytoplasm and the nucleus helps to characterise the link between the cytoskeleton and nucleoskeleton

tissue weakness in laminopathies. More recently, magnetic tweezer measurements were directly carried out on isolated nuclei (Guilluy et al. 2014) to reveal a nucleus-specific mechanotransduction pathway related to the LINC complex. Indeed, beads bound to nesprin 1 and subjected to repeated magnetic pulses led to progressive stiffening of isolated nuclei. Moreover, this stiffening was independent of nuclear actin and chromatin, but required intact lamins and emrin, the latter being phosphorylated in response to force (Guilluy et al. 2014).

Passive microrheometry, based on the analysis of the movement of nanoparticles injected in the cytoplasm and/or the nucleus, was extensively used to investigate nuclear structure and mechanics (Tseng et al. 2004), and the specific roles 
of lamin A/C (Lee et al. 2007) and LINC complex (Hale et al. 2008) in the whole-cell mechanics, in particular adhesion, polarisation and migration. These intracellular nanoscale measurements confirmed the mechanical continuity of the cell structure from cytoskeleton to nucleoskeleton, and the central role of the LINC complex in mechanotransduction and global cell coordination. Of note, internal active microrheometry was also made possible by the injection of magnetic nanorods in the nuclei of adherent cells and their manipulation at a distance with rotating magnetic fields (Celedon et al. 2011).

While microrheology of the cell/nucleus and mechanotransduction were extensively studied in the past years in animal cells, no such effort has been invested for walled cells, in particular in plants. This is quite surprising since plants are obviously mechanosensitive. It has been even shown, at the cell scale, that forces applied at the surface of tobacco cells could induce migration of the nucleus $(\mathrm{Qu}$ and Sun 2007). This could be due to the fact that some of the micromechanical methods reviewed here would be inefficient (too weak) to investigate plant cell structures that are mechanically shielded by the huge turgor pressure and cell wall. However, one could argue that measurements could be carried out on wall-less plant protoplasts as well as on isolated nuclei. In that respect, comparison between the mechanics of animal and wall-less plant cells is instructive (Durand-Smet et al. 2014). It will also be of interest to mechanically characterise isolated plant nuclei, as well as their interaction with cytoskeleton polymers in vitro (Stoppin et al. 1994). Such studies will help define differences and putative conserved core mechanosensing mechanisms between plants and animals (Asnacios and Hamant 2012). A first step in this endeavour might be the identification of some key players in plant nuclei (Fig. 1).

\section{Plant homologues in nuclear envelopes}

As in animals, plant nuclei display nuclear pore complexes; most of the nucleoporins are homologous to the vertebrate ones and contribute to the nucleocytoplasmic transport. Note that Nup136, which is unique to plants, dynamically interacts with the nuclear pore complex and may be considered as the functional homologue of the human Nup153 (Tamura et al. 2010).

Similarly, LINC complexes involving SUN-KASH proteins exist in plants, bridging the cytoskeleton to nucleoskeleton at the nuclear envelope. The SUN-interacting KASH proteins, located at the outer nuclear membrane, were mainly identified in Arabidopsis. They display a limited conservation with known opisthokont KASH proteins, except for AtTIK, which harbours a more classical KASH tail (Graumann et al. 2014). Specific SUN-KASH bridges were shown between AtSUN1, 2 proteins and AtWIP1-3, as well as between the mid-SUN AtSUN3-5 and AtTIK (Zhou et al. 2012; Graumann et al. 2014). Both AtWIPs and AtSINE1 are indirectly associated with actin filaments, notably through the physical interactions between ATWIT2 and the plantspecific Myosin XI-i (Tamura et al. 2013).

Although plant cells are devoid of a centrosome, the nuclear envelope constitutes a site of microtubule nucleation (Stoppin et al. 1994). $\gamma$-Tubulin complex proteins were identified in plants, including GCP2 and GCP3 proteins, which have nuclear targeting domains (Seltzer et al. 2007). GIPs (GCP3 interacting proteins) were first identified in plants as novel regulators of $\gamma$-tubulin complexes (Janski et al. 2008, 2012). Two GIP proteins are present in almost all plant genomes, whereas the GIP homologues in animals and Schizosaccharomyces pombe, called MOZART1 and MZT1, respectively, are single genes (Hutchins et al. 2010; Dhani et al. 2013). Contrary to the nuclear envelope functional components, GIPs are dynamic proteins found on both sides of the nuclear envelope, as well as at the nuclear pores (Batzenschlager et al. 2013). They interact with TSA1, which is located at the nuclear envelope and most probably the endoplasmic reticulum in interphase cells (Suzuki et al. 2005). Near the inner nuclear membrane, GIPs are located close to chromocentres and colocalise with centromeres (Batzenschlager et al. 2015). Because of the role of GIP in centromeric cohesion and in CENH3 loading, GIPs also contribute to centromere functions (Batzenschlager et al. 2013; Chabouté and Berr 2016). Therefore, the GIPs seem to bridge nuclear regulation and cytoplasmic microtubules at the nuclear envelope (Fig. 1).

At the inner nuclear membrane, Arabidopsis and maize SUN domain proteins exhibit the conserved features of their eukaryotes counterparts, with the existence of SUN1, SUN2 and mid-SUN homologues 3 to 5 (Graumann et al. 2010, 2014; Murphy et al. 2010). Whereas SUN1 and SUN2 are exclusively located at the nuclear envelope (Graumann et al. 2010), SUN3 and SUN4 share localisation between endoplasmic reticulum and nuclear envelope; SUN5 localisation has not yet been analysed (Graumann et al. 2014). The plantspecific NEAP1-3 proteins were also identified at the inner nuclear membrane in Arabidopsis and NEAP1 may be connected with chromatin through its interaction with a putative transcription factor (bZIP18, Pawar et al. 2016).

Near the inner nuclear membrane, a fibrous meshwork similar to the animal lamina was observed by field emission scanning electron microscopy (FE-SEM) in tobacco BY2 cells and was called "plamina" (Fiserova et al. 2009; Ciska and Moreno Díaz de la Espina 2014). While no homologues of lamins have been identified in plant genomes, functional candidates of the nuclear matrix beneath the nuclear envelope were characterised, such as the NMPC1 protein in carrot (Masuda et al. 1997), CRWN1, 4 (Dittmer et al. 2007) and KAKU4 (Goto et al. 2014) in Arabidopsis. 


\section{Mechanosensing through the nuclear envelope: candidates in plants}

Since structural changes of nuclear envelope proteins and chromatin are important features in mechanotransduction in animals and yeast (Dahl et al. 2008; Fedorchak et al. 2014), the following features will be considered as potential candidates in plant nuclear mechanosensing: nuclear deformability, link to nuclear envelope and chromatin remodelling.

All the nuclear envelope, the actors cited above are involved in shaping nuclei. In differentiated Arabidopsis cells, most of the corresponding mutants display smaller and spherical nuclei when compared to large elongated nuclei in the wild type (for a review, see Tamura et al. 2015). Interestingly, the gip1gip 2 nucleus shape is affected in both differentiated and undifferentiated cells, with enlarged nuclei exhibiting shape distortions such as lobes and indentations (Batzenschlager et al. 2013, 2014). Moreover gip mutants are also impaired in nuclear pore complex distribution and architecture. Interestingly, while some proteins, such as GIP1-2, SUN1-2, SUN4-5 and WIP1-3, share functional redundancy in shaping nuclei (Zhou et al. 2012; Graumann et al. 2014; Batzenschlager et al. 2013), other nuclear envelope proteins, such as SUN3, CRWN1, CRWN4, KAKU4, MYOSIN XI-I or Nup136, may have non-redundant functions (Tamura et al. 2010, 2013; Wang et al. 2013; Goto et al. 2014). More specifically, KAKU4-dependent nuclear deformation can be uncoupled from CRWN1 or CRWN4 (Goto et al. 2014), as SUN-WIP-WIT2-MyosinXI-i-dependent nuclear deformation can be uncoupled from CRWN1 (Zhou et al. 2015). Furthermore, CRWN1 and CRWN4 may have additive effects (Wang et al. 2013) since nuclear shape defects are stronger in the double mutant than in single mutants. In addition, in either witlwit2 or myosin XI-i mutants, root hair nuclear movement is impaired, suggesting that a nucleocytoplasmic continuum SUN-WIT-Myosin XI-i may contribute to an actin-mediated nuclear movement (Tamura et al. 2013).

Altogether these data suggest that nuclear shaping may be supported by both cytoplasmic forces transmitted to the nuclear envelope and by the plamina, KAKU4 and CRWN1 may maintain nuclear morphology through interactions with the nucleocytoplasmic linker, while Nup136 may mechanically support the nuclear envelope. Among these different actors, some were shown to have a direct or indirect link with chromatin through functional and proteomic analyses. The triple mutant sun 1 sun 4 sun 5 exhibits defect in chromatin compaction and up-regulation of heterochromatin silent information such as TSI1 (Poulet et al. 2017). NEAP3 is less tightly anchored to the inner nuclear membrane than NEAP1, and may, thus, contribute to its function in heterochromatin chromatin organisation (e.g. size and number of chromocentres, Pawar et al. 2016). CRWN4 controls higher order heterochromatin organisation and, most notably, the proper localisation of $5 \mathrm{~S}$ RNA and centromeric repeats (Wang et al. 2013). More recently, the carrot NMCP1 protein, equivalent to CRWN proteins in Arabidopsis, was used as a bait to identify nuclear candidates in Arabidopsis using the C-terminus part of the protein involved in its nuclear periphery localisation. Four proteins were identified: the nuclear localised actin-related protein 7 (ARP7), as well as the transcription factors MYBtype transcription factor 3 (MYB3), C3HC4 RING-finger proteins (SINAT1) and BES1-INTERACTING MYC-LIKE 1 (BIM1) involved in brassinosteroid signalling (Mochizuki et al. 2017). The identification of these interacting partners may shed new light on the role of the nuclear envelope in signalling, including mechanotransduction.

Because of their localisation on both sides of the nuclear envelope, GIPs may have a unique role in this picture, notably through their association with microtubule dynamics on the one hand, and their association with centromere and chromocentres in synergy with the epigenetic regulator MGO3/TSK (Batzenschlager et al. 2017), another TSA1 partner (Takeda et al. 2004), on the other hand. Consistently, GIPs could actively contribute to heterochromatin organisation, as the giplgip2 mutant displays heterogeneity in chromocentres size and number (Batzenschlager et al. 2013). Interestingly, cortical microtubules change their orientation in response to mechanical cues (Hamant et al. 2008; Landrein and Hamant 2013). Although it is unclear how plant cytoplasmic microtubules behave in response to stress, this echoes the contribution of actin filaments in nuclear mechanotransduction, through the indirect interactions between actin and lamina (Enyedi and Niethammer 2016; Aureille et al. 2017). These features also do not preclude the existence of cross-talks between microtubules and actin filaments in nuclear mechanotransduction (see e.g. Sampathkumar et al. 2011 for an analysis of structural dependencies between actin filaments and microtubules in plants).

\section{Conclusion: avenues for future research in plants}

The homologies between plant and animal potential nuclear mechanosensing pathways might echo conserved chromatin regulators and functions in both kingdoms. At the molecular level, a force in the cytoplasm will propagate to the nucleoplasm if it is not dissipated, i.e. if the LINC complex is sufficiently stiff and there is no reason to think that plants would be different from animals on that front; yet, this still needs to be formally demonstrated. Interestingly, during differentiation, or in the presence of stiffer mechanical environments, nuclear stiffness is increasing in mammals (Hampoelz and Lecuit 2011; Swift et al. 2013). This is due, in part, to the accumulation of lamins (Swift and Discher 2014) and the formation of a peripheral heterochromatin (Hampoelz and Lecuit 2011). The stiffness of the extracellular matrix has been thoroughly 
studied in plants, notably through decades of research on cell walls. Because cell wall stiffness can vary greatly between plant cell types or during differentiation, nuclear stiffening in cells with stiffer cell walls may also be visible in plants and help us understand how differentiation, in turn, affects gene expression. The relation between nucleus and wall stiffness has, however, not been assessed in plants so far.

Beyond the comparison between nuclear mechanosensing in plants and animals, a prospect for the future would be to unravel the actual mechanisms triggering gene expression changes. Several models involving direct mechanical perturbations on nucleus structure have been proposed: force-driven chromatin decondensation that would unmask binding sites for transcriptional regulators, force-induced chromatin detachment from the nuclear (p)lamina, moving loci away from the transcriptionally repressive nuclear periphery or force-driven conformation changes of inner nuclear envelope proteins, affecting transcriptional and chromatin regulators (Isermann and Lammerding 2013). Whether these mechanisms apply to plant nuclear mechanosensing is another exciting avenue for future research in both chromatin and mechanotransduction in plants.

Altogether, the accumulation of knowledge on the structural effectors of nuclei across kingdoms support the tensegrity concept, at least qualitatively (Ingber 2008). To demonstrate it with quantitative data will require a more thorough analysis. For instance, if microtubules, in parallel to actin, played a major role in nuclear mechanotransduction in plants, knowing that microtubules are roughly three orders of magnitude stiffer than actin filaments, at least in vitro (e.g. Gittes et al. 1993), this would inevitably affect the way forces are transduced to the nucleus. Furthermore, the added complexity of microtubule-associated proteins (and their impact on microtubule stiffness, see e.g. Portran et al. 2013) makes this endeavour both challenging and exciting.

Beyond the direct force propagation via the extracellular matrix-cytoskeleton-nuclear envelope continuum, mechanotransduction also occurs through more indirect ways. For instance, nuclear pore size may be modified in response to nuclear envelope stretching (Garcia et al. 2016). Alternatively, nuclear membrane may convert tension into biochemical signals, notably by mediating store release of $\mathrm{Ca}^{2+}$ at the outer nuclear membrane through mechanosensitive ion channels. For instance, the nuclear membrane protein, emerin, was recently shown to play a crucial role in nuclear structure and the production of transient nuclear $\mathrm{Ca}^{2+}$ peaks in animals (Shimojima et al. 2017). In that regard, nuclear pore complexes may play a similar role in calcium signalling in plants (Charpentier and Oldroyd 2013). Incidentally, a voltage-gated $\mathrm{Ca}^{2+}$ channel (DMI1 and CNGC15 proteins) at the nuclear envelope was recently shown to contribute to perinuclear calcium oscillation to establish plant-symbiont interactions in Medicago (Charpentier et al. 2016). Calcium signalling may also affect chromatin remodelling (Thuleau et al. 2012). In such a context, the role of Nup136 involved in nuclear shaping has to be explored, as well as that of TSA1 displaying a $\mathrm{Ca}^{2+}$ binding activity (Suzuki et al. 2005). Other indirect roles may involve the translocation of major effectors of mechanotransduction, such as $\beta$-catenin and Yap/Taz in animals (Janmey et al. 2013). The interplay between nuclear envelope mechanics and nuclear pore gating is, thus, another exciting prospect for future studies in plant nuclear mechanosensing.

Lastly, if gene expression is certainly a key aspect of mechanotransduction in development, one must recall that cells are, in principle, able to respond to mechanical cues, even without a nucleus. This was nicely shown on (enucleated) fish epidermal keratocytes, which became polar and even motile upon mechanical stimulation (Verkhovsky et al. 1999). Given the stereotypical cortical microtubule response to wall tension in plants, one may infer that this response may also not require transcriptional regulation, at least in the short term. The contribution of nuclear mechanosensing to these cortical mechanical responses, such as mechanotransduction buffering, amplification or robustness, is also likely to be a thriving field of research in the future.

Acknowledgements This work was supported by the European Research Council (ERC-2013-CoG-615,739 "MechanoDevo" to O.H.), 'Who Am I?' Labex (ANR-11-IDEX-0005-02 and ANR-11-LABX0071) to A.A., the Schlumberger Foundation for Education and Research to O.H. and CNRS (mécanobiologie « NEstress ») to M-E.C.

\section{Compliance with ethical standards}

Conflict of interest Kateryna Fal declares that she has no conflict of interest. Atef Asnacios declares that he has no conflict of interest. MarieEdith Chabouté declares that she has no conflict of interest. Olivier Hamant declares that he has no conflict of interest.

Ethical approval This article does not contain any studies with human participants or animals performed by any of the authors.

Open Access This article is distributed under the terms of the Creative Commons Attribution 4.0 International License (http:// creativecommons.org/licenses/by/4.0/), which permits unrestricted use, distribution, and reproduction in any medium, provided you give appropriate credit to the original author(s) and the source, provide a link to the Creative Commons license, and indicate if changes were made.

\section{References}

Anderson CM, Wagner TA, Perret M, He ZH, He D, Kohorn BD (2001) WAKs: cell wall-associated kinases linking the cytoplasm to the extracellular matrix. Plant Mol Biol 47:197-206

Apel ED, Lewis RM, Grady RM, Sanes JR (2000) Syne-1, a dystrophinand Klarsicht-related protein associated with synaptic nuclei at the neuromuscular junction. J Biol Chem 275:31986-31995. doi:10. 1074/jbc.M004775200 
Arsenovic PT, Ramachandran I, Bathula K et al (2016) Nesprin-2G, a component of the nuclear LINC complex, is subject to myosindependent tension. Biophys J 110:34-43. doi:10.1016/j.bpj.2015. 11.014

Asnacios A, Hamant O (2012) The mechanics behind cell polarity. Trends Cell Biol 22:584-591. doi:10.1016/j.tcb.2012.08.005

Aureille J, Belaadi N, Guilluy C (2017) Mechanotransduction via the nuclear envelope: a distant reflection of the cell surface. Curr Opin Cell Biol 44:59-67. doi:10.1016/j.ceb.2016.10.003

Bao G, Suresh S (2003) Cell and molecular mechanics of biological materials. Nat Mater 2:715-725. doi:10.1038/nmat1001

Batzenschlager M, Masoud K, Janski N et al (2013) The GIP gammatubulin complex-associated proteins are involved in nuclear architecture in Arabidopsis thaliana. Front Plant Sci 4:480. doi:10.3389/ fpls.2013.00480

Batzenschlager M, Herzog E, Houlné G, Schmit AC, Chabouté ME (2014) GIP/MZT1 proteins orchestrate nuclear shaping. Front Plant Sci 5:29. doi:10.3389/fpls.2014.00029

Batzenschlager M, Lermontova I, Schubert V, Fuchs J, Berr A, Koini MA, Houlné G, Herzog E, Rutten T, Alioua A, Fransz P, Schmit AC, Chabouté ME (2015) Arabidopsis MZT1 homologs GIP1 and GIP2 are essential for centromere architecture. Proceedings of the National Academy of Sciences. 112:8656-8660. doi:10.1073/pnas. 1506351112

Batzenschlager M, Schmit A-C, Herzog E et al (2017) MGO3 and GIP1 act synergistically for the maintenance of centromeric cohesion. Nucleus 8:98-105. doi:10.1080/19491034.2016.1276142

Bausch AR, Ziemann F, Boulbitch AA, Jacobson K, Sackmann E (1998) Local measurements of viscoelastic parameters of adherent cell surfaces by magnetic bead microrheometry. Biophys J 75:2038-2049. doi:10.1016/S0006-3495(98)77646-5

Biamonti G, Giacca M, Perini G et al (1992) The gene for a novel human lamin maps at a highly transcribed locus of chromosome 19 which replicates at the onset of S-phase. Mol Cell Biol 12:3499-3506. doi: 10.1128/MCB.12.8.3499

Braam J (2005) In touch: plant responses to mechanical stimuli. New Phytol 165:373-389. doi:10.1111/j.1469-8137.2004.01263.x

Broers JLV, Peeters EAG, Kuijpers HJH et al (2004) Decreased mechanical stiffness in LMNA-/- cells is caused by defective nucleocytoskeletal integrity: implications for the development of laminopathies. Hum Mol Genet 13:2567-2580. doi:10.1093/hmg/ ddh 295

Buxboim A, Swift J, Irianto J et al (2014) Matrix elasticity regulates lamin-A,C phosphorylation and turnover with feedback to actomyosin. Curr Biol 24:1909-1917. doi:10.1016/j.cub.2014.07.001

Caille N, Thoumine O, Tardy Y, Meister J-J (2002) Contribution of the nucleus to the mechanical properties of endothelial cells. J Biomech $35: 177-187$

Cazzonelli CI, Nisar N, Roberts AC, Murray KD, Borevitz JO, Pogson BJ (2014) A chromatin modifying enzyme, SDG8, is involved in morphological, gene expression, and epigenetic responses to mechanical stimulation. Front Plant Sci 5:533. doi:10.3389/fpls.2014. 00533

Celedon A, Hale CM, Wirtz D (2011) Magnetic manipulation of nanorods in the nucleus of living cells. Biophys J 101:1880-1886. doi: 10.1016/j.bpj.2011.09.008

Chabouté M-E, Berr A (2016) GIP contributions to the regulation of centromere at the interface between the nuclear envelope and the nucleoplasm. Front Plant Sci 7:118. doi:10.3389/fpls.2016.00118

Chambliss AB, Khatau SB, Erdenberger N et al (2013) The LINCanchored actin cap connects the extracellular milieu to the nucleus for ultrafast mechanotransduction. Sci Rep 3:1087. doi:10.1038/ srep01087

Charpentier M, Oldroyd GED (2013) Nuclear calcium signaling in plants. Plant Physiol 163:496-503. doi:10.1104/pp.113.220863
Charpentier M, Sun J, Martins TV et al (2016) Nuclear-localized cyclic nucleotide-gated channels mediate symbiotic calcium oscillations. Science 352:1102-1105. doi:10.1126/science. aae 0109

Chi YH, Chen CY, Jeang KT (2012) Reversal of laminopathies: the curious case of SUN1. Nucleus 3(5):418-21. doi:10.4161/nucl. 21714

Ciska M, Moreno Díaz de la Espina S (2014) The intriguing plant nuclear lamina. Front Plant Sci 5:166. doi:10.3389/fpls.2014.00166

Coutand C, Martin L, Leblanc-Fournier N, Decourteix M, Julien JL, Moulia B (2009) Strain mechanosensing quantitatively controls diameter growth and PtaZFP2 gene expression in poplar. Plant Physiol 151:223-232. doi:10.1104/pp.109.138164

Cota RR, Teixido-Travesa N, Ezquerra A, Eibes S, Lacasa C, Roig J, Luders J (2017) MZT1 regulates microtubule nucleation by linking $f$ ÁTuRC assembly to adapter-mediated targeting and activation. J Cell Sci 130:406-419. doi:10.1242/jcs.195321

Crisp M, Liu Q, Roux K et al (2006) Coupling of the nucleus and cytoplasm: role of the LINC complex. J Cell Biol 172:41-53. doi:10. 1083/jcb.200509124

D'Angelo MA, Raices M, Panowski SH, Hetzer MW (2009) Agedependent deterioration of nuclear pore complexes causes a loss of nuclear integrity in postmitotic cells. Cell 136:284-295. doi:10. 1016/j.cell.2008.11.037

Dahl KN, Kalinowski A (2011) Nucleoskeleton mechanics at a glance. J Cell Sci 124:675-678. doi:10.1242/jcs.069096

Dahl KN, Kahn SM, Wilson KL, Discher DE (2004) The nuclear envelope lamina network has elasticity and a compressibility limit suggestive of a molecular shock absorber. J Cell Sci 117:4779-4786. doi: $10.1242 /$ jcs. 01357

Dahl KN, Engler AJ, Pajerowski JD, Discher DE (2005) Power-law rheology of isolated nuclei with deformation mapping of nuclear substructures. Biophys J 89:2855-2864. doi:10.1529/biophysj.105. 062554

Dahl KN, Scaffidi P, Islam MF, Yodh AG, Wilson KL, Misteli T (2006) Distinct structural and mechanical properties of the nuclear lamina in Hutchinson-Gilford progeria syndrome. Proc Natl Acad Sci U S A 103:10271-10276. doi:10.1073/pnas.0601058103

Dahl KN, Ribeiro AJS, Lammerding J (2008) Nuclear shape, mechanics, and mechanotransduction. Circ Res 102:1307-1318. doi:10.1161/ CIRCRESAHA.108.173989

Dahl KN, Booth-Gauthier EA, Ladoux B (2010) In the middle of it all: mutual mechanical regulation between the nucleus and the cytoskeleton. J Biomech 43:2-8. doi:10.1016/j.jbiomech.2009.09.002

Dhani DK, Goult BT, George GM et al (2013) Mzt1/Tam4, a fission yeast MOZART1 homologue, is an essential component of the $\gamma$-tubulin complex and directly interacts with GCP3Alp6. Mol Biol Cell 24: 3337-3349. doi:10.1091/mbc.E13-05-0253

Di Francesco L, Totani L, Dovizio M et al (2009) Induction of prostacyclin by steady laminar shear stress suppresses tumor necrosis factor$\alpha$ biosynthesis via heme oxygenase- 1 in human endothelial cells. Circ Res 104:506-513. doi:10.1161/CIRCRESAHA.108.191114

Discher DE, Janmey P, Wang Y-L (2005) Tissue cells feel and respond to the stiffness of their substrate. Science 310:1139-1143. doi:10.1126/ science. 1116995

Discher DE, Mooney DJ, Zandstra PW (2009) Growth factors, matrices, and forces combine and control stem cells. Science 324:1673-1677. doi: $10.1126 /$ science. 1171643

Dittmer TA, Misteli T (2011) The lamin protein family. Genome Biol 12: 222. doi:10.1186/gb-2011-12-5-222

Dittmer TA, Stacey NJ, Sugimoto-Shirasu K, Richards EJ (2007) LITTLE NUCLEI genes affecting nuclear morphology in Arabidopsis thaliana. Plant Cell 19:2793-2803. doi:10.1105/tpc. 107.053231

Durand-Smet P, Chastrette N, Guiroy A et al (2014) A comparative mechanical analysis of plant and animal cells reveals convergence 
across kingdoms. Biophys J 107:2237-2244. doi:10.1016/j.bpj. 2014.10.023

Enyedi B, Niethammer P (2016) A case for the nuclear membrane as a mechanotransducer. Cell Mol Bioeng 9:247-251. doi:10.1007/ s12195-016-0430-2

Fabry B, Maksym GN, Butler JP, Glogauer M, Navajas D, Fredberg JJ (2001) Scaling the microrheology of living cells. Phys Rev Lett 87: 148102. doi:10.1103/PhysRevLett.87.148102

Fedorchak GR, Kaminski A, Lammerding J (2014) Cellular mechanosensing: getting to the nucleus of it all. Prog Biophys Mol Biol 115:76-92. doi:10.1016/j.pbiomolbio.2014.06.009

Field MC, Koreny L, Rout MP (2014) Enriching the pore: splendid complexity from humble origins: evolution of the nuclear pore complex. Traffic 15:141-156. doi:10.1111/tra.12141

Fiserova J, Kiseleva E, Goldberg MW (2009) Nuclear envelope and nuclear pore complex structure and organization in tobacco BY-2 cells. Plant J 59:243-255. doi:10.1111/j.1365-313X.2009.03865.x

Furukawa K, Inagaki H, Hotta Y (1994) Identification and cloning of an mRNA coding for a germ cell-specific A-type lamin in mice. Exp Cell Res 212:426-430. doi:10.1006/excr.1994.1164

Furusawa T, Rochman M, Taher L et al (2015) Chromatin de-compaction by the nucleosomal binding protein HMGN5 impairs nuclear sturdiness. Nat Commun 6:6138. doi:10.1038/ncomms7138

Garcia A, Rodriguez Matas JF, Raimondi MT (2016) Modeling of the mechano-chemical behaviour of the nuclear pore complex: current research and perspectives. Integr Biol 8:1011-1021. doi:10.1039/ C6IB00153J

Geitmann A (2010) Mechanical modeling and structural analysis of the primary plant cell wall. Curr Opin Plant Biol. 13(6):693-9. doi:10. 1016/j.pbi.2010.09.017

Gesson K, Rescheneder P, Skoruppa MP, von Haeseler A, Dechat T, Foisner R (2016) A-type lamins bind both hetero- and euchromatin, the latter being regulated by lamina-associated polypeptide 2 alpha. Genome Res 26:462-473. doi:10.1101/gr.196220.115

Gittes F, Mickey B, Nettleton J, Howard J (1993) Flexural rigidity of microtubules and actin filaments measured from thermal fluctuations in shape. J Cell Biol 120:923-934

Göb E, Schmitt J, Benavente R, Alsheimer M (2010) Mammalian sperm head formation involves different polarization of two novel LINC complexes. PLoS ONE 5,e12072. doi10.1371/journal.pone. 0012072

Godbole AS, Lu X, Guo X, Kassab GS (2008) NADPH oxidase has a directional response to shear stress. Am J Physiol Heart Circ Physiol 296:H152-H158. doi:10.1152/ajpheart.01251.2007

Goldman RD, Gruenbaum Y, Moir RD, Shumaker DK, Spann TP (2002) Nuclear lamins: building blocks of nuclear architecture. Genes Dev 16:533-547. doi:10.1101/gad.960502

Goto C, Tamura K, Fukao Y, Shimada T, Hara-Nishimura I (2014) The novel nuclear envelope protein KAKU4 modulates nuclear morphology in Arabidopsis. Plant Cell 26:2143-2155. doi:10.1105/tpc.113.122168

Graumann K, Runions J, Evans DE (2010) Characterization of SUNdomain proteins at the higher plant nuclear envelope. Plant $\mathrm{J}$ 61: 134-144. doi:10.1111/j.1365-313X.2009.04038.x

Graumann K, Vanrobays E, Tutois S, Probst AV, Evans DE, Tatout C (2014) Characterization of two distinct subfamilies of SUN-domain proteins in Arabidopsis and their interactions with the novel KASH-domain protein AtTIK. J Exp Bot 65:6499-6512. doi:10.1093/jxb/eru368

Green PB (1962) Mechanism for plant cellular morphogenesis. Science 138:1404-1405. doi:10.1126/science.138.3548.1404

Green PB, King A (1966) A mechanism for the origin of specifically oriented textures in development with special reference to Nitella wall texture. Aust J Biol Sci 19:421-437

Gruenbaum Y, Foisner R (2015) Lamins: nuclear intermediate filament proteins with fundamental functions in nuclear mechanics and genome regulation. Annu Rev Biochem 84:131-164. doi:10.1146/ annurev-biochem-060614-034115
Guilak F, Tedrow JR, Burgkart R (2000) Viscoelastic properties of the cell nucleus. Biochem Biophys Res Commun 269:781-786. doi:10. $1006 /$ bbrc. 2000.2360

Guilluy C, Osborne LD, Van Landeghem L et al (2014) Isolated nuclei adapt to force and reveal a mechanotransduction pathway within the nucleus. Nat Cell Biol 16:376-381. doi:10.1038/ncb2927

Hagan I, Yanagida M (1995) The product of the spindle formation gene sad1+ associates with the fission yeast spindle pole body and is essential for viability. J Cell Biol 129:1033-1047. doi:10.1083/jcb. 129.4.1033

Hale CM, Shrestha AL, Khatau SB et al (2008) Dysfunctional connections between the nucleus and the actin and microtubule networks in laminopathic models. Biophys J 95:5462-5475. doi:10.1529/ biophysj.108.139428

Hamant O (2013) Widespread mechanosensing controls the structure behind the architecture in plants. Curr Opin Plant Biol 16:654 660. doi:10.1016/j.pbi.2013.06.006

Hamant O, Heisler MG, Jönsson H et al (2008) Developmental patterning by mechanical signals in Arabidopsis. Science 322:1650-1655. doi: 10.1126/science. 1165594

Hampoelz B, Lecuit T (2011) Nuclear mechanics in differentiation and development. Curr Opin Cell Biol 23:668-675. doi:10.1016/j.ceb. 2011.10.001

Hampoelz B, Azou-Gros Y, Fabre R, Markova O, Puech PH, Lecuit T (2011) Microtubule-induced nuclear envelope fluctuations control chromatin dynamics in Drosophila embryos. Development 138: 3377-3386. doi:10.1242/dev.065706

Haswell ES, Phillips R, Rees DC (2011) Mechanosensitive channels: what can they do and how do they do it? Structure 19:1356-1369. doi:10.1016/j.str.2011.09.005

Hatch EM, Hetzer MW (2016) Nuclear envelope rupture is induced by actin-based nucleus confinement. J Cell Biol 215:27-36. doi:10. $1083 /$ jcb. 201603053

Heisler MG, Hamant O, Krupinski P et al (2010) Alignment between PIN1 polarity and microtubule orientation in the shoot apical meristem reveals a tight coupling between morphogenesis and auxin transport. PLoS Biol 8:e1000516. doi:10.1371/journal.pbio. 1000516

Hejnowicz Z, Rusin A, Rusin T (2000) Tensile tissue stress affects the orientation of cortical microtubules in the epidermis of sunflower hypocotyl. J Plant Growth Regul 19:31-44

Hochmuth RM (2000) Micropipette aspiration of living cells. J Biomech 33:15-22

Hodzic DM, Yeater DB, Bengtsson L, Otto H, Stahl PD (2004) Sun2 is a novel mammalian inner nuclear membrane protein. J Biol Chem 279:25805-25812. doi:10.1074/jbc.M313157200

Höger TH, Krohne G, Franke WW (1988) Amino acid sequence and molecular characterization of murine lamin B as deduced from cDNA clones. Eur J Cell Biol 47:283-290

Hu S, Chen J, Butler JP, Wang N (2005) Prestress mediates force propagation into the nucleus. Biochem Biophys Res Commun 329:423428. doi:10.1016/j.bbrc.2005.02.026

Hutchins JRA, Toyoda Y, Hegemann B et al (2010) Systematic analysis of human protein complexes identifies chromosome segregation proteins. Science 328:593-599. doi:10.1126/science.1181348

Ingber DE (2003) Mechanosensation through integrins: cells act locally but think globally. Proc Natl Acad Sci U S A 100:1472-1474. doi: 10.1073/pnas.0530201100

Ingber DE (2008) Tensegrity-based mechanosensing from macro to micro. Prog Biophys Mol Biol 97:163-179. doi:10.1016/j.pbiomolbio. 2008.02.005

Isermann P, Lammerding J (2013) Nuclear mechanics and mechanotransduction in health and disease. Curr Biol 23:R1113R1121. doi:10.1016/j.cub.2013.11.009 
Janmey PA, Wells RG, Assoian RK, McCulloch CA (2013) From tissue mechanics to transcription factors. Differentiation 86:112-120. doi: 10.1016/j.diff.2013.07.004

Janski N, Herzog E, Schmit AC (2008) Identification of a novel small Arabidopsis protein interacting with gamma-tubulin complex protein 3. Cell Biol Int 32:546-548. doi:10.1016/j.cellbi.2007.11.006

Janski N, Masoud K, Batzenschlager M et al (2012) The GCP3interacting proteins GIP1 and GIP2 are required for $\gamma$-tubulin complex protein localization, spindle integrity, and chromosomal stability. Plant Cell 24:1171-1187. doi:10.1105/tpc.111.094904

Jensen GS, Fal K, Hamant O, Haswell ES (2017) The RNA polymeraseassociated factor 1 complex is required for plant touch responses. J Exp Bot 68:499-511. doi:10.1093/jxb/erw439

Khatau SB, Bloom RJ, Bajpai S et al (2012) The distinct roles of the nucleus and nucleus-cytoskeleton connections in threedimensional cell migration. Sci Rep 2:488. doi:10.1038/srep00488

Knepper C, Savory EA, Day B (2011) Arabidopsis NDR1 is an integrinlike protein with a role in fluid loss and plasma membrane-cell wall adhesion. Plant Physiol 156:286-300. doi:10.1104/pp.110.169656

Korfali N, Wilkie GS, Swanson SK et al (2012) The nuclear envelope proteome differs notably between tissues. Nucleus 3:552-564. doi: 10.4161/nucl.22257

Lammerding J, Schulze PC, Takahashi T et al (2004) Lamin A/C deficiency causes defective nuclear mechanics and mechanotransduction. J Clin Invest 113:370-378. doi:10.1172/ JCI19670

Lammerding J, Fong LG, Ji JY et al (2006) Lamins A and C but not lamin B1 regulate nuclear mechanics. J Biol Chem 281:25768-25780. doi: 10.1074/jbc.M513511200

Landrein B, Hamant O (2013) How mechanical stress controls microtubule behavior and morphogenesis in plants: history, experiments and revisited theories. Plant J 75:324-338. doi:10.1111/tpj.12188

Lecuit T, Lenne P-F (2007) Cell surface mechanics and the control of cell shape, tissue patterns and morphogenesis. Nat Rev Mol Cell Biol 8: 633-644. doi:10.1038/nrm2222

Lee JSH, Hale CM, Panorchan P et al (2007) Nuclear lamin A/C deficiency induces defects in cell mechanics, polarization, and migration. Biophys J 93:2542-2552. doi:10.1529/biophysj.106.102426

Lin F, Worman HJ (1993) Structural organization of the human gene encoding nuclear lamin A and nuclear lamin C. J Biol Chem 268: $16321-16326$

Lin F, Worman HJ (1995) Structural organization of the human gene (LMNB1) encoding nuclear lamin B1. Genomics 27:230-236. doi: 10.1006/geno.1995.1036

Lin T-C, Neuner A, Flemming D, Liu P, Chinen T, Jäkle U, Arkowitz R, Schiebel E (2016) MOZART1 and $\gamma$-tubulin complex receptors are both required to turn $\gamma$-TuSC into an active microtubule nucleation template. J Cell Biol 215:823-840. doi:10.1083/jcb.201606092

Liu J, Rolef Ben-Shahar T, Riemer D et al (2000) Essential roles for Caenorhabditis elegans lamin gene in nuclear organization, cell cycle progression, and spatial organization of nuclear pore complexes. Mol Biol Cell 11:3937-3947

Liu Q, Pante N, Misteli Tet al (2007) Functional association of Sun1 with nuclear pore complexes. J Cell Biol 178:785-798. doi:10.1083/jcb. 200704108

Liu H, Wen J, Xiao Y et al (2014) In situ mechanical characterization of the cell nucleus by atomic force microscopy. ACS Nano 8:38213828. doi:10.1021/nn500553z

Lombardi ML, Jaalouk DE, Shanahan CM, Burke B, Roux KJ, Lammerding J (2011) The interaction between nesprins and sun proteins at the nuclear envelope is critical for force transmission between the nucleus and cytoskeleton. J Biol Chem 286:2674326753. doi:10.1074/jbc.M111.233700

Lu D, Kassab GS (2011) Role of shear stress and stretch in vascular mechanobiology. J R Soc Interface 8:1379-1385. doi:10.1098/rsif. 2011.0177
Lüke Y, Zaim H, Karakesisoglou I et al (2008) Nesprin-2 Giant (NUANCE) maintains nuclear envelope architecture and composition in skin. J Cell Sci 121:1887-1898. doi:10.1242/jcs.019075

McGee MD, Rillo R, Anderson AS, Starr DA (2006) UNC-83 IS a $\mathrm{KASH}$ protein required for nuclear migration and is recruited to the outer nuclear membrane by a physical interaction with the SUN protein UNC- 84. Mol Biol Cell 17:1790-1801. doi10.1091/ mbc.E05-09-0894

Maniotis AJ, Chen CS, Ingber DE (1997) Demonstration of mechanical connections between integrins, cytoskeletal filaments, and nucleoplasm that stabilize nuclear structure. Proc Natl Acad Sci U S A 94: 849-854

Margalit A, Liu J, Fridkin A, Wilson KL, Gruenbaum Y (2005) A lamindependent pathway that regulates nuclear organization, cell cycle progression and germ cell development. Novartis Found Symp 264:231-240, discussion 240-245

Masuda K, Xu Z-J, Takahashi S et al (1997) Peripheral framework of carrot cell nucleus contains a novel protein predicted to exhibit a long $\alpha$-helical domain. Exp Cell Res 232:173-181. doi:10.1006/ excr.1997.3531

Masuda H, Toda T (2016) Synergistic role of fission yeast Alp16GCP6 and Mzt1MOZART1 in $\gamma$-tubulin complex recruitment to mitotic spindle pole bodies and spindle assembly. Mol Biol Cell 27:17531763. doi:10.1091/mbc.E15-08-0577

Mislow JM, Holaska JM, Kim MS et al (2002) Nesprin-1 $\alpha$ self-associates and binds directly to emerin and lamin A in vitro. FEBS Lett 525: 135-140. doi:10.1016/S0014-5793(02)03105-8

Mochizuki R, Tsugama D, Yamazaki M, Fujino K, Masuda K (2017) Identification of candidates for interacting partners of the tail domain of DcNMCP1, a major component of the Daucus carota nuclear lamina-like structure. Nucleus 8:312-322. doi:10.1080/19491034. 2017.1280210

Mohr D, Frey S, Fischer T, Güttler T, Görlich D (2009) Characterisation of the passive permeability barrier of nuclear pore complexes. EMBO J 28:2541-2553. doi:10.1038/emboj.2009.200

Monshausen GB, Haswell ES (2013) A force of nature: molecular mechanisms of mechanoperception in plants. J Exp Bot 64:4663-4680. doi:10.1093/jxb/ert204

Morgan JT, Pfeiffer ER, Thirkill TL et al (2011) Nesprin-3 regulates endothelial cell morphology, perinuclear cytoskeletal architecture, and flow-induced polarization. Mol Biol Cell 22:4324-4334. doi: 10.1091/mbc.E11-04-0287

Mosley-Bishop KL, Li Q, Patterson K, Fischer JA (1999) Molecular analysis of the klarsicht gene and its role in nuclear migration within differentiating cells of the Drosophila eye. Curr Biol 9:1211-1220

Murphy SP, Simmons CR, Bass HW (2010) Structure and expression of the maize (Zea mays L.) SUN-domain protein gene family: evidence for the existence of two divergent classes of SUN proteins in plants. BMC Plant Biol 10:269. doi:10.1186/1471-2229-10-269

Nakajima N, Abe K (1995) Genomic structure of the mouse A-type lamin gene locus encoding somatic and germ cell-specific lamins. FEBS Lett 365:108-114

Nakamura M, Yagi N, Kato T, Fujita S, Kawashima N, Ehrhardt DW, Hashimoto T (2012) Arabidopsis GCP3-interacting protein 1/ MOZART 1 is an integral component of the c-tubulin-containing microtubule nucleating complex. Plant J 71:216-225. doi:10.1111/j. 1365-313X.2012.04988.x

Nakayama N, Smith RS, Mandel T et al (2012) Mechanical regulation of auxin-mediated growth. Curr Biol 22:1468-1476. doi:10.1016/j. cub.2012.06.050

Neelam S, Chancellor TJ, Li Y et al (2015) Direct force probe reveals the mechanics of nuclear homeostasis in the mammalian cell. Proc Natl Acad Sci U S A 112:5720-5725. doi:10.1073/pnas.1502111112

Obado SO, Brillantes M, Uryu K et al (2016) Interactome mapping reveals the evolutionary history of the nuclear pore complex. PLoS Biol 14:e1002365. doi:10.1371/journal.pbio.1002365 
Paddy MR, Belmont AS, Saumweber H, Agard DA, Sedat JW (1990) Interphase nuclear envelope lamins form a discontinuous network that interacts with only a fraction of the chromatin in the nuclear periphery. Cell 62:89-106

Padmakumar VC, Abraham S, Braune S et al (2004) Enaptin, a giant actin-binding protein, is an element of the nuclear membrane and the actin cytoskeleton. Exp Cell Res 295:330-339. doi:10.1016/j. yexcr.2004.01.014

Padmakumar VC, Libotte T, Lu W (2005) The inner nuclear membrane protein Sun1 mediates the anchorage of Nesprin-2 to the nuclear envelope. J Cell Sci 118:3419-3430. doi:10.1242/jcs.02471

Pajerowski JD, Dahl KN, Zhong FL, Sammak PJ, Discher DE (2007) Physical plasticity of the nucleus in stem cell differentiation. Proc Natl Acad Sci U S A 104:15619-15624. doi:10.1073/pnas. 0702576104

Paredez AR, Somerville CR, Ehrhardt DW (2006) Visualization of cellulose synthase demonstrates functional association with microtubules. Science 312:1491-1495. doi:10.1126/science.1126551

Pawar V, Poulet A, Détourné G et al (2016) A novel family of plant nuclear envelope-associated proteins. J Exp Bot 67:5699-5710. doi:10.1093/jxb/erw332

Peter M, Kitten GT, Lehner CF et al (1989) Cloning and sequencing of cDNA clones encoding chicken lamins $\mathrm{A}$ and $\mathrm{B} 1$ and comparison of the primary structures of vertebrate A- and B-type lamins. J Mol Biol 208:393-404

Poh Y-C, Shevtsov SP, Chowdhury F et al (2012) Dynamic force-induced direct dissociation of protein complexes in a nuclear body in living cells. Nat Commun 3:866. doi:10.1038/ncomms 1873

Portran D, Zoccoler M, Gaillard J et al (2013) MAP65/Ase1 promote microtubule flexibility. Mol Biol Cell 24:1964-1973. doi:10.1091/ mbc.E13-03-0141

Pouille P-A, Ahmadi P, Brunet A-C, Farge E (2009) Mechanical signals trigger Myosin II redistribution and mesoderm invagination in Drosophila embryos. Sci Signal 2:ra16. doi: 10.1126/scisignal. 2000098

Poulet A, Duc C, Voisin M et al (2017) The LINC complex contributes to heterochromatin organisation and transcriptional gene silencing in plants. J Cell Sci 130:590-601. doi:10.1242/jcs.194712

Qu L-H, Sun M-X (2007) The plant cell nucleus is constantly alert and highly sensitive to repetitive local mechanical stimulations. Plant Cell Rep 26:1187-1193. doi:10.1007/s00299-007-0343-6

Rowat AC, Lammerding J, Ipsen JH (2006) Mechanical properties of the cell nucleus and the effect of emerin deficiency. Biophys J 91:4649 4664. doi:10.1529/biophysj.106.086454

Sampathkumar A, Lindeboom JJ, Debolt S et al (2011) Live cell imaging reveals structural associations between the actin and microtubule cytoskeleton in Arabidopsis. Plant Cell 23:2302-2313. doi:10. 1105/tpc. 111.087940

Schäpe J, Prausse S, Radmacher M, Stick R (2009) Influence of lamin A on the mechanical properties of amphibian oocyte nuclei measured by atomic force microscopy. Biophys J 96:4319-4325. doi:10.1016/ j.bpj.2009.02.048

Schirmer EC, Florens L, Guan T, Yates JR, Gerace L (2003) Nuclear membrane proteins with potential disease links found by subtractive proteomics. Science 301:1380-1382. doi:10.1126/science.1088176

Schmidt HB, Görlich D (2016) Transport selectivity of nuclear pores, phase separation, and membraneless organelles. Trends Biochem Sci 41:46-61. doi:10.1016/j.tibs.2015.11.001

Schreiner SM, Koo PK, Zhao Y, Mochrie SG, King MC (2015) The tethering of chromatin to the nuclear envelope supports nuclear mechanics. Nat Commun 6:7159. doi:10.1038/ncomms8159

Schwartz C, Fischer M, Mamchaoui K et al (2017) Lamins and nesprin-1 mediate inside-out mechanical coupling in muscle cell precursors through FHOD1. Sci Rep 7:1253. doi:10.1038/s41598-017-01324-Z

Seltzer V, Janski N, Canaday J et al (2007) Arabidopsis GCP2 and GCP3 are part of a soluble $\gamma$-tubulin complex and have nuclear envelope targeting domains: targeting of $\gamma$-tubulin complex proteins. Plant $\mathrm{J}$ 52:322-331. doi:10.1111/j.1365-313X.2007.03240.x

Shaklai S, Amariglio N, Rechavi G, Simon AJ (2007) Gene silencing at the nuclear periphery. FEBS J 274:1383-1392. doi:10.1111/j.17424658.2007.05697.x

Sherrard K, Robin F, Lemaire P, Munro E (2010) Sequential activation of apical and basolateral contractility drives ascidian endoderm invagination. Curr Biol 20:1499-1510. doi:10.1016/j.cub.2010.06.075

Shih H-W, Miller ND, Dai C, Spalding EP, Monshausen GB (2014) The receptor-like kinase FERONIA is required for mechanical signal transduction in Arabidopsis seedlings. Curr Biol 24:1887-1892. doi:10.1016/j.cub.2014.06.064

Shimi T, Kittisopikul M, Tran J et al (2015) Structural organization of nuclear lamins A, C, B1, and B2 revealed by superresolution microscopy. Mol Biol Cell 26:4075-4086. doi:10.1091/mbc.E15-070461

Shimojima M, Yuasa S, Motoda C et al (2017) Emerin plays a crucial role in nuclear invagination and in the nuclear calcium transient. Sci Rep 7:44312. doi:10.1038/srep44312

Shin J-W, Spinler KR, Swift J, Chasis JA, Mohandas N, Discher DE (2013) Lamins regulate cell trafficking and lineage maturation of adult human hematopoietic cells. Proc Natl Acad Sci U S A 110: 18892-18897. doi:10.1073/pnas. 1304996110

Shyy JY-J, Chien S (2002) Role of Integrins in endothelial mechanosensing of shear stress. Circ Res 91:769-775. doi:10. 1161/01.RES.0000038487.19924.18

Solovei I, Wang AS, Thanisch K et al (2013) LBR and Lamin A/C sequentially tether peripheral heterochromatin and inversely regulate differentiation. Cell 152:584-598. doi:10.1016/j.cell.2013.01. 009

Starr DA, Fridolfsson HN (2010) Interactions between nuclei and the cytoskeleton are mediated by SUN-KASH nuclear-envelope bridges. Annu Rev Cell Dev Biol 26:421-444. doi:10.1146/annurevcellbio-100109-104037

Stephens AD, Banigan EJ, Adam SA, Goldman RD, Marko JF (2017) Chromatin and lamin A determine two different mechanical response regimes of the cell nucleus. Mol Biol Cell 28:1984-1996. doi: 10.1091/mbc.E16-09-0653

Stewart C, Burke B (1987) Teratocarcinoma stem cells and early mouse embryos contain only a single major lamin polypeptide closely resembling lamin B. Cell 51:383-392

Stewart-Hutchinson PJ, Hale CM, Wirtz D, Hodzic D (2008) Structural requirements for the assembly of LINC complexes and their function in cellular mechanical stiffness. Exp Cell Res 314:1892-1905. doi:10.1016/j.yexcr.2008.02.022

Stoppin V, Vantard M, Schmit AC, Lambert AM (1994) Isolated plant nuclei nucleate microtubule assembly: the nuclear surface in higher plants has centrosome-like activity. Plant Cell 6:1099-1106. doi:10. 1105/tpc.6.8.1099

Suzuki T, Nakajima S, Morikami A, Nakamura K (2005) An Arabidopsis protein with a novel calcium-binding repeat sequence interacts with TONSOKU/MGOUN3/BRUSHY1 involved in meristem maintenance. Plant Cell Physiol 46:1452-1461. doi:10.1093/pcp/pci155

Swift J, Discher DE (2014) The nuclear lamina is mechano-responsive to ECM elasticity in mature tissue. J Cell Sci 127:3005-3015. doi:10. $1242 /$ jcs. 149203

Swift J, Ivanovska IL, Buxboim A et al (2013) Nuclear lamin-A scales with tissue stiffness and enhances matrix-directed differentiation. Science 341:1240104. doi:10.1126/science.1240104

Takeda S, Tadele Z, Hofmann I et al (2004) BRU1, a novel link between responses to DNA damage and epigenetic gene silencing in Arabidopsis. Genes Dev 18:782-793. doi:10.1101/gad.295404

Tamura K, Fukao Y, Iwamoto M, Haraguchi T, Hara-Nishimura I (2010) Identification and characterization of nuclear pore complex components in Arabidopsis thaliana. Plant Cell 22:4084-4097. doi:10. $1105 /$ tpc. 110.079947 
Tamura K, Iwabuchi K, Fukao Y et al (2013) Myosin XI-i links the nuclear membrane to the cytoskeleton to control nuclear movement and shape in Arabidopsis. Curr Biol 23:1776-1781. doi:10.1016/j. cub.2013.07.035

Tamura K, Goto C, Hara-Nishimura I (2015) Recent advances in understanding plant nuclear envelope proteins involved in nuclear morphology. J Exp Bot 66:1641-1647. doi:10.1093/jxb/erv036

Thorpe SD, Lee DA (2017) Dynamic regulation of nuclear architecture and mechanics - a rheostatic role for the nucleus in tailoring cellular mechanosensitivity. Nucleus 8:287-300. doi:10.1080/19491034. 2017.1285988

Thoumine O, Ott A, Cardoso O, Meister JJ (1999) Microplates: a new tool for manipulation and mechanical perturbation of individual cells. J Biochem Biophys Methods 39:47-62

Thuleau P, Brière C, Mazars C (2012) Recent advances in plant cell nuclear signaling. Mol Plant 5:968-970. doi:10.1093/mp/sss083

Tseng Y, Lee JSH, Kole TP, Jiang I, Wirtz D (2004) Micro-organization and visco-elasticity of the interphase nucleus revealed by particle nanotracking. J Cell Sci 117:2159-2167. doi:10.1242/jcs.01073

Tzima E, Irani-Tehrani M, Kiosses WB, Dejana E (2005) A mechanosensory complex that mediates the endothelial cell response to fluid shear stress. Nature 437:426-431. doi:10.1038/ nature 03952

Uyttewaal M, Burian A, Alim K et al (2012) Mechanical stress acts via katanin to amplify differences in growth rate between adjacent cells in Arabidopsis. Cell 149:439-451. doi:10.1016/j.cell.2012.02.048

Verkhovsky AB, Svitkina TM, Borisy GG (1999) Self-polarization and directional motility of cytoplasm. Curr Biol 9:11-20

Vigouroux C, Auclair M, Dubosclard E et al (2001) Nuclear envelope disorganization in fibroblasts from lipodystrophic patients with heterozygous $\mathrm{R} 482 \mathrm{Q} / \mathrm{W}$ mutations in the lamin $\mathrm{A} / \mathrm{C}$ gene. J Cell Sci 114:4459-4468

Vogel V, Sheetz M (2006) Local force and geometry sensing regulate cell functions. Nat Rev Mol Cell Biol 7:265-275. doi:10.1038/nrm1890

Vogel V, Sheetz MP (2009) Cell fate regulation by coupling mechanical cycles to biochemical signaling pathways. Curr Opin Cell Biol 21: 38-46. doi:10.1016/j.ceb.2009.01.002
Wang N, Tytell JD, Ingber DE (2009) Mechanotransduction at a distance: mechanically coupling the extracellular matrix with the nucleus. Nat Rev Mol Cell Biol 10:75-82. doi:10.1038/nrm2594

Wang H, Dittmer TA, Richards EJ (2013) Arabidopsis CROWDED NUCLEI (CRWN) proteins are required for nuclear size control and heterochromatin organization. BMC Plant Biol 13:200. doi:10. 1186/1471-2229-13-200

Williamson RE (1990) Alignment of cortical microtubules by anisotropic wall stresses. Aust J Plant Physiol 17:601-613

Wilson KL, Foisner R (2010) Lamin-binding proteins. Cold Spring Harb Perspect Biol 2:a000554. doi:10.1101/cshperspect.a000554

Wolf S, Hématy K, Höfte H (2012) Growth control and cell wall signaling in plants. Annu Rev Plant Biol 63:381-407. doi:10.1146/annurevarplant-042811-105449

Xie W, Chojnowski A, Boudier T et al (2016) A-type lamins form distinct filamentous networks with differential nuclear pore complex associations. Curr Biol 26:2651-2658. doi:10.1016/j.cub.2016.07.049

Zhen Y-Y, Libotte T, Munck M, Noegel AA, Korenbaum E (2002) NUANCE, a giant protein connecting the nucleus and actin cytoskeleton. J Cell Sci 115:3207-3222

Zhou X, Graumann K, Evans DE, Meier I (2012) Novel plant SUNKASH bridges are involved in RanGAP anchoring and nuclear shape determination. J Cell Biol 196:203-211. doi:10.1083/jcb. 201108098

Zhou X, Graumann K, Wirthmueller L, Jones JD, Meier I (2014) Identification of unique SUNinteracting nuclear envelope proteins with diverse functions in plants. J Cell Biol 205:677. doi:10.1083/ jcb.201401138

Zhou X, Groves NR, Meier I (2015) Plant nuclear shape is independently determined by the SUN-WIP-WIT2-myosin XI-i complex and CRWN1. Nucleus 6:144-153. doi:10.1080/19491034.2014. 1003512

Zwerger M, Medalia O (2013) From lamins to lamina: a structural perspective. Histochem Cell Biol 140:3-12. doi:10.1007/s00418-0131104-y 